\title{
LAS ERAS IMAGINARIAS E LA EXPRESIÓN AMERICANA: \\ UMA REINVENCÃO IMAGÉTICA DA AMÉRICA LATINA
}

\section{LAS ERAS IMAGINARIAS AND LA EXPRESIÓN AMERICANA: AN IMAGINARY REINVENTION OF THE LATIN AMERICA}

\author{
Ximena Antonia DÍAZ MERINO ${ }^{104}$
}

\begin{abstract}
RESUMO: Para Lezama Lima a miscigenação cultural e racial não representa subdesenvolvimento, pelo contrário, representa a revanche do colonizado, ou em termos lezameanos a contraconquista. A partir do conceito de contraconquista o ensaísta aborda o processo que envolve a passagem do puramente europeu para o indo-afro-iberoamericano e através do conceito de 'eras imaginárias' reconstrói a continuidade da história cultural americana, uma releitura e reconstrução imaginárias do passado. Assim, mediante a imagem, a memória e a palavra, aplicadas às diversas épocas históricas da América, seria possível concatenar a vida do povo americano a partir dos mitos tanto indígenas quanto europeus, da conquista $\mathrm{e}$ contraconquista; do barroco e da utopia; do desterro romântico e do enraizamento estancieiro.
\end{abstract}

PALAVRAS-CHAVE: Barroco; Imaginário; Rsistência cultural; Lezama Lima.

\begin{abstract}
According to Lezama Lima the cultural and racial miscegenation does not represent underdevelopment, on the contrary, it represents the colonized people's revenge or, in Lima's words, the counter-conquest. From the counter-conquest concept the essayist treats the process that involves the transition from the purely European to the Indo-Afro-Iberoamerican and through the concept of "Imaginary Era" he reconstructs the American Cultural History continuity, an imaginary reinterpretation of the past as well as an imaginary reconstruction it. Therefore, facing the image, the memory and the word, applied to the various historical ages of America, it would be possible to relate the American peoples' life by taking into consideration: the Indigenous myths as well as the Europeans' myths, the conquest and the counter-conquest, the Baroque and the utopia, the romantic exile and the ranchers'settlement.
\end{abstract}

KEYWORDS: Baroque; Imaginary; Cultural resistance; José Lezama Lima.

104 Programa de Pós-Graduação em Letras (campus Cascavel - PR). Centro de Ciências Humanas, Educação e Letras (campus Marechal Cândido Rondon - PR). Universidade Estadual do Oeste do Paraná (UNIOESTE) - PR - Brasil - CEP 85960-000 - xdmerino@,ig.com.br 
A interação entre espanhóis, índios e negros proporcionou uma nova forma ao Barroco espanhol. Esta nova expressão artística denominada Barroco de Índias expressou uma crise social, histórica, cultural e artística que pode ser observada, por exemplo, na proliferação decorativa das igrejas espanholas construídas no Novo Mundo. Os elementos iconográficos nativos misturados aos europeus constituem um processo encoberto de influência mútua que deu origem a um novo conceito de beleza, da mesma forma as aquisições linguísticas, tanto espanholas quanto hispano-americanas, outorgaram uma nova forma de expressão ao idioma espanhol.

Para José Lezama Lima (1910-1976), que concebeu sua visão americanista nos anos cinquenta do século passado, a miscigenação cultural e racial não representa subdesenvolvimento, pelo contrário, representa a revanche do colonizado, ou em termos lezameanos a contraconquista. A partir do conceito de contraconquista o ensaísta cubano aborda o processo que envolve a passagem do puramente europeu para o indoafro-ibero-americano e através do conceito de 'eras imaginárias' reconstrói a continuidade da história cultural americana, uma releitura e reconstrução imaginárias do passado. Desta maneira, mediante a imagem, a memória e a palavra, aplicadas às diversas épocas históricas da América, seria possível concatenar a vida do povo americano a partir dos mitos tanto indígenas quanto europeus, da conquista e contraconquista; do barroco e da utopia; do desterro romântico e do enraizamento estancieiro.

Seguindo o pensamento de Lezama Lima, a contraconquista seria a catástrofe da qual surgiu a cultura hispano-americana, fato que para Carlos Fuentes (1992, p.217):

[...] configura nuestra historia como un conflicto de valores en el cual ninguno es destruido por su contrario sino que, 'trágicamente' cada uno se resuelve en el otro. La 'tragedia' sería así, prácticamente, una definición de nuestro mestizaje.

Dentro desse contexto, o que o ensaísta cubano objetiva é restaurar essa visão 'trágica' na imaginação americana e nesse sentido vê na palavra estrangeira o elemento fundador do maravilhoso, ou seja, a palavra como força representativa do universo latino-americano. A fundação da linguagem barroca da contraconquista representa uma resistência à ideia de que o modelo latino-americano deve pautar-se pela história cultural do colonizador europeu. Como é de conhecimento geral, os cronistas foram nomeando a flora e a fauna americanas a partir de seu imaginário medieval contido nas 
lendas, fábulas e histórias de viagens, como afirma Lezama Lima em La imagen de América Latina (2000, p. 467):

El cronista de Indias trae sus imágenes ya hechas y el nuevo paisaje se las resquebraja. El señor barroco comienza su retorcimiento y rebrillos anclado en los fabularios y los mitos grecolatinos, pero muy pronto la incorporación de los elementos fitomorfos y zoomorfos que están en su acecho, lagartos, colibries, coyotes, ombú, ceiba, hylamhylam, crean nuevos fabularios que le otorgan una nueva gravitación a su obra $[\ldots]$.

A necessidade de nomear as coisas e os seres do Novo Mundo foi destacada por Alejo Carpentier ao resgatar as cartas de Hernán Cortés dirigidas ao rei da Espanha. Cartas que enfatizam a necessidade de nomear:

'Por no saber poner los nombres a las cosas, no las expreso' [e Carpentier acrescentou], 'es un problema que vamos a confrontar nosotros, los escritores de América, muchos siglos más tarde. Y es la búsqueda del vocabulario ${ }^{105}$.

Para Lezama Lima a contraconquista se expressa através da linguagem do barroco mestiço, uma linguagem de resistência mediante a qual o homem latinoamericano revela sua experiência subjetiva. Barroco da contraconquista, da miscigenação e da transculturação constituída a partir de "eras imaginárias", porque, como afirma Lezama Lima (2000, p.210), "el mundo real es la imagen [...] Creo que todo lo percibimos por imagen. [...] La imagen es la misma realidad y lo que alcanzamos de la realidad es la imagen", posto que a realidade se percebe através da imagem, e a distância existente entre o homem e a realidade é atravessada por ela, de tal maneira que é mediante a imago - a representação de uma ideia, a correlação entre um objeto e seu significado para a mente de cada indivíduo - que se conhece a realidade. E será a partir do conceito de imago que Lezama Lima chegará a compreender a identidade cultural como uma visão coletiva da história.

De acordo com Lezama Lima, o primeiro momento da configuração da cultura hispano-americana o constitui o esforço para interpretar a natureza americana realizado pelos cronistas europeus, os que resgatavam as imagens que constituíam seu universo 
medieval para reinterpretar metaforicamente a nova paisagem, desta interação entre $o$ conhecido e o desconhecido surgiram os primeiros relatos sobre o Novo Mundo. O processo consistia em fazer um paralelo por semelhança, confrontando a paisagem, a flora e a fauna preconcebidas com os novos elementos americanos e o que não tinha comparação era definido através do tato, do olfato e da visão. Mediante este confronto imagético entre o invisível, universo medieval europeu, e a proliferação de imagens visíveis que configuravam o Novo Mundo, os cronistas iniciaram o registro da história da América a partir de um processo metafórico que deu forma a uma nova cultura, uma nova história que nascia da comparação de desigualdades.

Lezama Lima apresenta os fundamentos de sua teoria da imagem em Las eras imaginarias (1982, p.44), conjunto de ensaios escritos entre 1958 e 1968, nos quais especifica as condições necessárias para que uma era imaginária aconteça:

[...] esas eras imaginarias tienen que surgir en grandes fondos temporales, ya milenios, ya situaciones excepcionales, que se hacen arquetípicas, que se congelan donde la imagen las puede apresar al repetirse. En los milenios, exigidos por una cultura, donde la imagen actúa en determinadas circunstancias excepcionales, al convertirse el hecho, en una viviente causalidad metafórica, es donde se sitúan esas eras imaginarias. La historia de la poesía no puede ser otra cosa que el estudio y expresión de las eras imaginarias.

O poeta cubano desenvolveu um raciocínio que resume o devir americano como uma era imaginária, a qual acrescenta e transforma fragmentos de outros imaginários, com suas semelhanças e diferenças, construindo dessa maneira o relato do devir americano. Frente à dificuldade do homem americano em entender a formação de sua cultura, Lezama Lima se fez as seguintes perguntas:

En qué forma la imagen ha creado cultura, en qué espacios esa imagen resultó más suscitante, y sobre todo en qué forma la imagen actúa en la historia, tiene virtud operante, son preguntas que sólo la poesía y la novela pueden ir contestando. (MATAIX, 2005).

Para responder essas interrogações o ensaísta cubano propôs uma historiografia tecida pela imagem que opera sobre a tradição cultural, selecionando aqueles momentos em que os fatos se convertem em símbolos culturais.

Sobre o conceito de imago desenvolvido por Lezama Lima, Saúl Yurkievich entende que: “[...] la imago es el motor de la historia. La imagen preside y configura 
las realizaciones históricas; mediante ellas lo imaginario se efectúa: las realizaciones históricas son efectuaciones imaginantes" (2002, p.816). Então, se pode afirmar que a história se constrói mediante um processo interpretativo que se inicia no fato concreto de um tempo histórico determinado registrado pela expressão escrita, e que esse fato ao ser decodificado pelo leitor é novamente interpretado absorvendo um significado social, o que constitui uma reconstrução histórica através da imagem emanada desse fato histórico traduzido para a escrita e logo decodificado pelo sujeito leitor, o que nas palavras de Lezama Lima (1969, p.9) é:

[...] la forma de devenir en que un paisaje va hacia un sentido, una interpretación o una sencilla hermenéutica, para ir después hacia su reconstrucción, que es en definitiva lo que marca su eficacia o desuso, su fuerza ordenancista o su apagado eco, que es su visión histórica.

Portanto, o que o autor quer dizer é que o importante não é o fato histórico em si, mas sua interpretação, sua reconstrução, aspecto que determinará a eficácia ou desuso desse fato. Em Las eras imaginarias (1971), o autor cubano faz referência às culturas e às épocas que têm ficado plasmadas na memória da humanidade e que se têm perpetuado através da imagem que projetaram. Por outro lado em La expresión americana (1957), Lezama Lima, tinha enunciado os personagens que atuaram nessas culturas ou épocas e que através de suas ações conseguiram perpetuar sua imagem na história de seus povos. Uma concepção de mundo que o autor explica em La cantidad hechizada (1970, p.51) com as seguintes palavras: "Cuando el pueblo está habitado por una imagen viviente, el estado alcanza su figura. El hombre que muere en la imagen gana la sobreabundancia de la resurrección [...]". Dessa maneira os povos participam da criação de sua imagem, o que assegura sua persistência na memória cultural e, logo, na história. Assim, os momentos privilegiados da história desvelam a trama que alimenta a imaginação transformadora de um simples fato em conhecimento poético. A visão do autor cubano se apoia nos mitos que se encontram nos atos nascentes da humanidade e enfatiza o uso de método mítico como forma de reconstruir a narrativa histórica, como o explica na citação a seguir:

Todo tendrá que ser reconstruido, invencionado de nuevo, y los viejos mitos, al reaparecer de nuevo, nos ofrecerán sus conjuros y sus enigmas con un rostro desconocido. La ficción de los mitos son los nuevos mitos, con nuevos cansancios y terrores (LEZAMA LIMA, 1969, p.16). 
Nessa reconstrução, a literatura deve preservar as épocas que outorgaram riqueza ao movimento social possibilitando o surgimento de grandes períodos, ou seja:

Una obra debe lograr, el surgimiento de imágenes temporales por medio de miradas y retinas, hasta corroer en su visión la imagen de la muerte. Una visión en pro de la reconstrucción de las imágenes y los recuerdos dispersos, como inconsciente de la memoria de los pueblos (LEZAMA LIMA, 1968, p.161-162).

Em La expresión americana Lezama Lima apresenta uma multiplicidade de imagens míticas, simbólicas e arquetípicas para configurar a expressão cultural da América. O poeta cubano transita pelo imaginário americano a partir de personagens brilhantes que se têm destacado na história americana, mas muitas vezes resgata personalidades escuras, esquecidas e marginais ausentes na história oficial da América.

Lezama Lima inicia o ensaio constatando que a origem do Barroco americano se encontra nos mitos originários, como o do Popol Vuh $h^{106}$, e através do mito maia tenta explicar o denominado problematismo americano ${ }^{107}$. A partir das figuras de Hunanpú e Ixbalanqué, representantes da astúcia e da ousadia do ser americano, Lezama Lima (1969, p.21) desenha a imagem dos heróis cosmogônicos, já os senhores de Xibalbá representam o colonizador:

Lo primero que nos despierta en el Popol Vuh, es el predominio del espíritu del mal, los señores de Xibalbá ven rodar los mundos, afianzándose su poderío y su terrible dominio de la naturaleza. Los impasibles contemplan el fracaso de cuantas tretas se establecen para echar a rodar su mandato, que parece estar implacablemente por encima de la naturaleza y de los animales más sutiles.

$106 \mathrm{O}$ Popol Vuh é o mais precioso legado mítico e teogónico da antiguidade americana. A primeira parte relata a origem do mundo e a criação do homem; a segunda parte, as façanhas dos heróis míticos Hunahpú e Ixbalanqué: testemunho da qualidade espiritual da cultura que originou a obra.

107 Com o conceito de problematismo americano Lezama Lima faz referência à concepção, tanto para o colonizador quanto para o colonizado, de que a miscigenação representa uma impureza cultural. In: LEZAMA LIMA, 1969. p 22. 
No relato maia, Hunanpú e Ixbalanqué descem ao inferno, lutam contra os senhores de Xibalbá e depois de muitas derrotas alcançam a vitória definitiva libertando a humanidade e criando um novo estatuto tribal.

No capítulo seguinte, ao se referir ao século XVIII, Lezama Lima (1969, p.34) cria a figura do “[...] 'señor barroco': “primer americano que va surgiendo dominador de sus caudales [...]" e que vai absorvendo a paisagem e a natureza americana reinterpretando-a desde dentro, a partir de sua vivência nesse hábitat. Uma toma de consciência que o faz conceber sua paisagem de forma diferente à do europeu, posto que:

El primer americano que va surgiendo dominador de sus caudales es nuestro señor barroco [...] Ese americano señor barroco, auténtico primer instalado en lo nuestro, en su granja, canonjía o casa de buen regalo [...] aparece cuando se han alejado del tumulto de la conquista y la parcelación del paisaje del colonizador (LEZAMA LIMA, 1969, p.35).

Esse primeiro americano é dono da paisagem que habita e, portanto, tem o poder de modificá-la e de reinterpretá-la, assume sua imagem e começa a defender seus interesses culturais de acordo com sua própria visão de mundo rejeitando o modelo imposto pelo europeu. Para o ensaísta cubano um exemplo desta ruptura pode ser observada através da 'indiatidade' do ser americano representada na figura do índio José Kodori, artista que encontrou uma maneira de preservar sua cultura mediante a inclusão camuflada dos símbolos indígenas americanos nas construções coloniais. Para tal façanha Kondori colocou junto das colunas gregas e dos anjos rococós o violão e a meia-lua incaica. Lezama Lima $(1969$, p.36) relata a ação do índio José Kondori com as seguintes palavras:

En los preciosos trabajos del indio Kondori [...] se observa la introducción de una temeridad, de un asombro: la indiatidade. En la portada de San Lorenzo, de Potosí, en medio a los angelotes larvales, de las colgantes hojas de piedra, de las llaves que como galeras navegan por la piedra labrada, aparece suntuosa, hierática, una princesa incaica, con todos sus atributos de poderio y desdén.

Fato muito significativo para esse momento histórico posto que o fechado mundo teológico europeu estava sendo invadido de forma sutil e definitiva, momento 
em que se rompia a unidade da arte europeia se rendendo ao incaico, configurando uma arte nova. Neste momento não se deve deixar de destacar a poeta Sor Juana Inés de la Cruz, nem a Antonio Francisco Lisboa (o Aleijadinho) que junto com Kondori configuram as primeiras três vozes barrocas latino-americanas, manifestações do caráter primordial do senhor barroco americano. A partir dessas personalidades, o Barroco latino-americano introduz um novo conceito de beleza. Contudo, para Lezama Lima esta nova concepção de beleza não se manifesta somente na arte, senão também está na natureza americana, posto que a paisagem constitui uma imagem muito significativa para o grupo humano que a habita. De acordo com o poeta cubano a imagem que emana da paisagem é captada pelo indivíduo e este a relaciona com os elementos de seu universo, e o resultado será a visão histórica dessa determinada cultura. A essa interpretação da imagem que emana da paisagem, Lezama Lima (1969, p.111) denomina 'era imaginária', pois:

Ante todo, el paisaje nos lleva a la adquisición del punto de mira, del campo óptico y el contorno [...] En América dondequiera que surge posibilidad de paisaje, tiene que existir posibilidad de cultura.

Ao ingressar no século XIX Lezama Lima não alude cronologicamente aos acontecimentos do período da independência, senão que cria a figura do 'rebelde romântico' para apresentar personagens da independência hispano-americana que tiveram destinos infelizes, foram mortos, presos, perseguidos ou excluídos. Lezama Lima (1969, p.77-78) confessa que: "Para ilustrar el XIX hemos escogido las figuras que nos parecen más esencialmente románticas por la frustración”, como por exemplo, Simón Rodríguez, Francisco Miranda ou José Martí e a seguir explica o porquê de sua seleção:

[...] esa gran tradición romántica del siglo XIX, la del calabozo, la ausencia, la imagen y la muerte logra crear el hecho americano, cuyo destino está más hecho de ausencias posibles que de presencias imposibles. La tradición de las ausencias posibles ha sido la gran tradición americana y donde se sitúa el hecho histórico que se ha logrado. José Martí representa en una gran navidad verbal, la plenitud de la ausencia posible.

Logo Lezama Lima (1969, p.100) exalta a imagem do poeta popular e do senhor estancieiro, que ilustram a reinvenção do castelhano com a expressão criolla: 
[...] en ese siglo de nueva andadura del romancero agrandada por el vaquero gauchesco, la masa de palabras que estaba congelada en lo gris recibió con él una lanza, que la puso a fluir de nuevo sobre el río.

Finalmente Lezama Lima (1969, p.118) destaca os "poetas de los comienzos", artistas criadores de obras que dialogam com a natureza, fator importante para o pensamento lezameano, posto que:

Después del señor barroco, bien instalado en el centro de su disfrute, el paisaje recobra una imantación más poderosa y demoníaca. El hombre desplazado de su centro, vuelve a él aunque su paisaje se muestre irreconciliable, ya para siempre lejano (LEZAMA LIMA, 1969, p.113).

O que se tem intentado ressaltar ao apresentar este sintético panorama do conteúdo de La expresión americana é chamar a atenção para as figuras do "señor barroco", do "rebelde romántico", do "poeta popular" e do "poeta de los comienzos", já que são imagens de personagens fictícios através dos quais Lezama Lima define momentos da cultura americana. Uma sequência que revela diferentes épocas, regiões e grupos sociais com a finalidade de detectar tipos de imaginação, momentos em que se deu a potencialidade para criar imagens que configuram eras imaginárias, posto que quando "[...] la imagen actúa sobre determinadas circunstancias excepcionales, al convertirse el hecho en una viviente causalidad metafórica, es donde se sitúan esas eras imaginarias" (LEZAMA LIMA, 1982, p.44).

Portanto, a diferença entre uma era imaginária e uma cultura está em que a primeira aconteceria ocasionalmente dentro da segunda ou poderia coincidir com ela, sempre e quando o fato se transforme em "una viviente causalidad metafórica". Ou seja, uma era imaginária seria um desabrochar dentro de uma cultura e este afloramento teria a capacidade de transcender as culturas donde foram geradas e, portanto, poderiam ressurgir em outras culturas. Lezama Lima (1988, p.462) chega a afirmar que uma era imaginária pode ser transgeográfica, transcultural e trans-histórica já que "Las culturas pueden desaparecer sin destruir las imágenes que ellas evaporaron [...] Las culturas van hacia su ruina, pero después de la ruina vuelven a vivir por la imagen". Um exemplo da resurreição da imagem está, de acordo com Lezama Lima (1982, p.51), na 
figura de Martí que, "como el hechizado Hernando de Soto ${ }^{108}$, ha sido enterrado y desenterrado, hasta que ha ganado su paz". Enfim, o conjunto da obra de José Lezama Lima pode ser considerado uma reinvenção imagética da América, uma forma de explicar o mundo a partir da imagem, uma reconstrução de sua história cultural a partir da releitura do passado histórico.

\section{REFERÊNCIAS}

CARPENTIER, A. Novela e historia en El recurso del método de Alejo Carpentier. MEC. Disponível em: http://escritoriodocentes.educ.ar/recursospdf/lengua/novela e historia alejo_carpentier. pdf

FUENTES, C. Valiente mundo nuevo: épica, utopía y mito en la novela hispanoamericana. $1^{\mathrm{a}}$ reimpr. México: F.C.E, 1992.

LEZAMA LIMA, J. La expresión americana. Santiago de Chile: Ed. Universitaria, 1969.

La cantidad hechizada. Habana: Ediciones Unión - UNEAC, 1970.

Las eras imaginarias. 2a ${ }^{\text {a }}$ Ed. Madrid: Ed. Fundamentos, 1982.

. Imágenes de América Latina. Memorias de América Latina, Caracas: Universidad Central de Venezuela, n.19, 1988.

. A Los Grandes Todos. Montevideo: Editorial Arca. 1968.

Palabras con José Lezama Lima: La imagen para mí es la vida. In: JIMÉNEZ EMÁN, G. Talud, Revista Literaria, Mérida, Venezuela, n.7/8, año IV, p.5-18, mayo de 1975.

La imagen de América. In: FERNANDEZ MORENO, C. (Coord.) América Latina en su literatura. $17^{a}$ ed. "Serie América Latina en su cultura". México: Siglo XXI, 2000. p. 462-468.

Diccionario - vida y obra de José Lezama Lima. Ed. Iván González Cruz. Valencia: Generalitat Valenciana, 2000.

. Paradiso. $2^{\text {a }}$ ed. Madrid: Paris: México: Buenos Aires: São Paulo: Rio de Janeiro: Lima: ALLCA XX, 1996. (Colección Archivos 3)

MATAIX, R. José Lezama Lima y la "Reinvención de América". Alicante: Biblioteca Cervantes, 2005.

YURKIEVICH, S. La expresión americana o la fabulación autóctona. Revista Iberoamericana, Pittsburgh, Vol. LXVIII, no 200, p.81, Julio-Septiembre, 2002.

108 Hernando de Soto, "[...] gobernador de Cuba y conquistador de La Florida, cuyo cadáver - en su segundo enterramiento, para evitar su profanación por los indios - fue echado al Missisipi en el tronco ahuecado de un árbol, interesó profundamente a Lezama, por su amistad con Atahualpa, por su coincidencia con Fernán Ponce de León, buscador de la Fuente de la Juventud y sobre todo por su condición de 'hechizado' que navega por el río 'sobrevive tres años después de su muerte, vuelve muerto para recoger a su esposa y volver a pasear en su castillo'.” In: LEZAMA LIMA, 1996, p.491. 
Artigo recebido em 28/08/2012

Aceito para publicação em 24/09/2012 